$1-1-2019$

\title{
Research Knowledge of Advanced Standing and Traditional Students: Implications for BSW Education
}

Jennifer L. K. Charles

The Catholic University of America

Nathan H. Perkins

Loyola University Chicago, nperkins2@luc.edu

Christopher J. Ward

Winthrop University

Melissa L. Stewart

Virginia Commonwealth University

Mary C. Secret

Virginia Commonwealth University

Follow this and additional works at: https://ecommons.luc.edu/socialwork_facpubs

Part of the Social Work Commons

\section{Recommended Citation}

Charles, Jennifer L. K.; Perkins, Nathan H.; Ward, Christopher J.; Stewart, Melissa L.; and Secret, Mary C.. Research Knowledge of Advanced Standing and Traditional Students: Implications for BSW Education. Journal of Baccalaureate Social Work, 24, 1: 27-47, 2019. Retrieved from Loyola eCommons, Social Work: School of Social Work Faculty Publications and Other Works, http://dx.doi.org/10.18084/

1084-7219.24.1.27

This Article is brought to you for free and open access by the Faculty Publications and Other Works by Department at Loyola eCommons. It has been accepted for inclusion in Social Work: School of Social Work Faculty Publications and Other Works by an authorized administrator of Loyola eCommons. For more information, please contact ecommons@luc.edu.

\section{(c) $($ ) $\odot \odot$}

This work is licensed under a Creative Commons Attribution-Noncommercial-No Derivative Works 3.0 License.

(c) The Association of Baccalaureate Social Work Program Directors, 2019. 


\title{
Research Knowledge of Advanced Standing and Traditional Students: Implications for BSW Education
}

\author{
JENNIFER L. K. CHARLES \\ NATHAN H. PERKINS \\ CHRISTOPHER J. WARD \\ MELISSA L. STEWART \\ MARY C. SECRET
}

The advanced standing model of social work education, which affords graduate credit to qualified BSW students who pursue their MSW, has not been without issue or controversy, including questions of potential differences in performance on various educational outcomes. Specifically related to research curriculum, the importance of which is often not wholly embraced by students, this article reports the results of a secondary data analysis comparing research knowledge among advanced standing and traditional MSW students as well as among the various undergraduate majors (i.e., BSW, psychology, and sociology). Results suggest that research knowledge is similar and low across student subgroups. Important differences in research knowledge were found among student groups based on undergraduate major, with BSW undergraduates without advanced standing, on average, scoring lower than any other group. Implications for BSW research curriculum are considered.

KEYWORDS BSW education, research, advanced standing, curriculum development

In 1974 the National Association of Social Workers (NASW) implemented a referendum recognizing baccalaureate-level social workers as fully professional (Sheafor, 2001). Until this time, undergraduate social work education was considered preprofessional or vocational—not a professional degree (Daley, 2015; Raymond \& Atherton, 1991). With this change, questions as to the difference between BSW- and MSW-level social work education were asked and answered: bachelor of social work (BSW) programs would prepare generalist practitioners and students for graduate programs, and master's of social work (MSW) programs would train specialist practitioners (Sheafor, 2001). The advanced standing model of education in social work has been offered since graduate schools of social work adopted an action by the Council on Social Work Education (CSWE) in 1978, affording graduate credit to students who earned their undergraduate degree in social work.

The Journal of Baccalaureate Social Work, Vol. 24 (2019)

(C) 2019, The Association of Baccalaureate Social Work Program Directors. All rights reserved 
The implementation of the advanced standing model was not without issue or controversy, including questions as to the differences in performance among advanced standing (AS) students, students with BSWs pursuing their MSWs without advanced standing, and traditional MSW students. This article adds to the literature around this issue, reporting the results of a secondary data analysis comparing research knowledge among AS and nonadvanced standing (NAS) MSW students, including those with and without BSW degrees, and other undergraduate majors, using data collected during the initial development and evaluation of the Research Knowledge Assessment (RKA; Secret, Abell, Ward, Charles, \& Perkins, 2017). The article concludes with suggestions for BSW research curriculum and programmatic changes that could be implemented to better prepare generalist social work practitioners to be competent in researchinformed practice and practice-informed research, as well as to better prepare BSW students for MSW-level research coursework, both with and without AS. As more than 20\% of MSW degrees in 2013-2014 and 2014-2015 and 25\% in 2015-2016 were conferred to AS students, the topic is of special concern to BSW program directors and educators (CSWE, 2015a, 2016, 2017).

\section{Literature Review}

Evolving out of the mass expansion of public services in the 1960s, fueled in part by the War on Poverty, schools of social work began offering undergraduate degrees to fulfill the staffing needs of new public agencies (Bremner \& Zastrow, 2008). With the advent of the BSW, social work education has been conceptualized as a continuum (Raymond \& Atherton, 1991), with a certain foundation underlying the profession, necessary for generalist practice, and instruction on more specialized knowledge and concentration skills provided at the graduate level. Both degrees are regarded as "professional" with graduates capable of varying levels of practice — generalist and advanced. At the graduate level, foundation (generalist) content is offered in the first year of study and concentration content in the second. For BSWs, foundation content is provided in the final years of undergraduate study.

The AS model developed to accommodate high-performing BSW graduates who pursued their MSWs within a limited time. These students, rather than retake redundant content, join traditional 2-year MSW students in the concentration year, presumably with the same foundation of knowledge related to human behavior, research, and generalist practice. It has been argued that understanding social work education as a continuum may not be as useful as hoped. Researchers have suggested different guiding goals for both programs: 
Rather than prepare generalist practitioners, Raymond and Atherton (1991) argued that BSW programs should train students for case management positions. Indeed, social work stands alone in this manner of education, when compared to the traditional professions of medicine, law, and theology (Raymond \& Atherton, 1991). These professions offer their professional coursework at the graduate level with preprofessional undergraduate programs. Given that social work differs markedly, the question of comparability between the level of performance of AS and traditional students has been asked, although research on the topic is minimal, with results mostly supportive of similarities between the groups (i.e., Carrillo \& Thyer, 1994; Jani et al., 2009; Knight, 1993) with some exception (O’Neil, 1980).

The ambiguous construct, level of performance, has been operationalized in several different ways. In one of the earlier studies comparing AS and NAS MSW students, conducted shortly after the introduction of the advanced standing model, O'Neil (1980) employed self-ratings on self-concept measures and supervisors' ratings of practice skills of recent MSW graduates, those with and without AS. Fortune, Green, and Kolevzon (1987) used graduate school academic performance as the main comparison criterion. Overall capability in field placement was another means of assessing level of performance that was employed by a few authors (Carrillo \& Thyer, 1994; Knight, 1993). Thyer, Vonk, and Tandy (1996) used students' licensure exams scores as a measure. Jani et al. (2009) were more specific in the type of performance to be measured, and they were particularly interested in specialized work with substance-abusing clients. Their outcome measures included self-report measures of perceived preparedness and perceived knowledge to work with clients displaying substance-abuse issues.

The results of these studies have mostly been supportive of the equality of performance of AS and NAS students, no matter how the outcome variable was operationalized. Fortune et al.'s (1987) investigation of MSW students at a large, mid-Atlantic, public university found that AS students and NAS graduate students without BSWs performed similarly in graduate school. However, and related to the present study, these researchers did find that BSW students who did not have AS, and were thus NAS, performed poorly at the graduate level, regardless of their undergraduate grade point average. The studies conducted by Carrillo and Thyer (1994) and Thyer et al. (1996) at a large, southern, public university both concluded that AS students performed at least as well as other MSW students, finding no significant differences between the two groups in terms of interviewing skills and licensure exam outcomes, respectively. Knight's (1993) findings were similar, finding no differences between AS and NAS 
students on field instructor evaluations. At a large, urban, mid-Atlantic university, Jani et al. (2009) found no differences between AS and NAS MSW students' perceived preparedness and knowledge of work with substance-abusing clients. On the other hand, and not supportive of the equality of AS and NAS students' performance, O'Neil's (1980) study found that AS graduates did not perform as well as NAS graduates, on average, receiving lower ratings than their counterparts on supervisors' assessments of practice skills. Again, it is important to remember that O'Neil's study included students from eight graduate programs in social work was conducted shortly after the introduction of the AS model of social work education. Last, Specht, Britt, and Frost (1984) compared MSW graduates with BSW and BA degrees from seven public universities in California and found that MSW grads without a BSW scored higher on 5 of 10 indicators of professional achievement than MSW grads with a BSW. What is quite surprising in this literature review is the absence of more recent comparisons of AS and NAS students on any educational outcome including acquired research knowledge.

As a profession, social work has embraced the expectation that students will be capable of competently engaging in research-informed practice and practiceinformed research, as reflected in CSWE's Educational Competency 4 (CSWE, 2015b). This expectation is primarily grounded in the belief that social work practitioners require research knowledge to ensure that their practices are of the utmost quality, both by keeping abreast of current evidence-based practices and being able to assess one's own practice. Secondarily, a strong research culture in social work is essential to maintain relevancy alongside other professions (Beddoe, 2011). Despite this codified commitment, concerns exist because of the lack of clear guidance on implementation.

Further complicating the task of preparing students to engage in evidencebased practice, the importance of research is not wholly embraced by students, regardless of AS status, who are often reluctant (Ponnuswami \& Harris, 2017), as they may view research curriculum as irrelevant, a punishment, and even intensely anxiety-provoking (Epstein, 1987; Gredig \& Bartlesen-Raemy, 2018; Maschi, Wells, Slater, MacMillan, \& Ristow, 2013; Morgenshtern, Freymond, Agyapong, \& Greeson, 2011; Nelson, 1983). Furthermore, and reflective of the key role of a student's undergraduate major on research performance, the literature suggests that social work students, AS or NAS, report higher levels of anxiety about research, have less interest in it (Green, Bretzin, Leininger, \& Stauffer, 2001; Royse \& Rompf, 1992), and feel even less confident compared to students in other majors (Freymond et al., 2014). Therefore, it is imperative for educators to attempt to understand what contributes to students' success. 
This investigation, which turns the focus to graduate students with BSWs, builds on previous work that examined research knowledge acquisition and retention of MSW students (Secret et al., 2017) by comparing AS and NAS MSW students on their research knowledge, using the RKA. The following research questions are addressed in this investigation: As measured by the RKA, are there differences in research knowledge between AS and NAS students, and are there differences between BSW undergraduate majors and other majors regarding research knowledge? The goal in comparing these student groups is to identify areas of the BSW research curriculum for targeted intervention as well as potential programmatic-level suggestions to strengthen the research culture to ensure that BSW graduates are best prepared for research-informed generalist practice and optimal performance at the graduate level.

\section{Method}

\section{Research Knowledge Assessment Project}

Emerging from the need to assess MSW student research learning at the host institution, the researchers developed the RKA, a process described in great detail elsewhere (Secret et al., 2017). Briefly, the RKA was designed as a program assessment and research project to examine research knowledge acquisition and retention for MSW students as they matriculated through the institution's research course sequence. Harlen's (2007) definition of construct validity, which is concerned with how what is assessed is in agreement with the learning outcome intended, was considered in the creation of the RKA instrument. To achieve this agreement, Harlen suggested developing an assessment instrument internally. This was accomplished in the RKA's development by engaging course instructors and their materials, including syllabi, tests, writing assignments, and social work research textbooks in the creation of the instrument. It was hoped that this would also increase reliability by engaging multiple instructors to ensure the instrument's applicability to multiple sections of the course rather than be solely colored through the lenses of the primary investigators. As created, the RKA is a vignette-based multiplechoice assessment. Consisting of four vignettes and 25 questions, the RKA focuses on five learning areas: (1) understanding how literature informs practicerelevant research questions and theory development (Theory subscale, seven questions), (2) the applicability and feasibility of qualitative and quantitative research designs (Design subscale, four questions), (3) measurement concepts and applications (Measurement subscale, seven questions), (4) sampling and 
data collection methods (Sampling subscale, four questions), and (5) ethical conduct and practice applications for social work researchers (Ethics and Practice subscale, three questions) (Secret et al., 2017).

The RKA, translated into three versions to prevent test-retest effects, was administered over a 3-year period to all students during their research classes, as they progressed through the MSW program: A pretest was given at the start of the foundation year research course, Posttest 1 at the end of the same foundation year research course, and Posttest 2 at the beginning of the concentration year research course. Approval from the host institution's Internal Review Board was received prior to beginning the study.

For the current study, only responses from consenting participants at Posttest 2 , administered at the beginning of the concentration year research course, representing the second research course in the MSW program (AS students were assumed to have completed a research methods course in their BSW program, which was a prerequisite for acceptance into the advanced standing program) were analyzed ( $N=336)$; AS students did not take the pretest or Posttest 1 , which were administered in the foundation year for NAS students.

For each question, participant responses were recoded as a correct-incorrect dichotomous variable in SPSS. Secret et al. (2017) provided a substantial rationale for the use of the RKA regarding reliability, which centers on the difficulty of the questions instead of a construct. Reliability analyses for this particular sample using the Kuder-Richardson 20 (KR-20) for dichotomous data indicated $\alpha=.591$, which falls below some commonly accepted thresholds (DeVellis, 2017). However, DeVellis (2017) also acknowledged that "it is not unusual to see published scales with lower alphas" (p.145). As noted by Quaigrain and Arhin (2017), assessments made by teachers (similar to the vignettes constructed for this research project) should have reliability coefficients around .50 to .60 (Rudner \& Schafer, 2002). McGahee and Ball (2009) noted that for exams including various concepts, a reliability coefficient of more than .50 can be considered good.

Length of the assessment must also be considered when interpreting the KR20. Bodner (1980) noted that KR-20 coefficients will increase simply with an increase in the number of questions. Based on the equation Bodner presented in his article, had there been 50 questions including the same material as the 25 questions in the RKA, the KR-20 would have increased from $\alpha=.591$ to $\alpha=.743$, which by DeVellis's (2017, p. 145) interpretation would constitute a "respectable" alpha. Based on the supporting evidence above, the KR-20 for this particular research project can be considered sufficient, given the novelty of the RKA and its use with this selective group of participants. However, future 
investigation into the underlying factor structure with a larger sample of individuals is warranted.

\section{Procedures}

Because the initial research project (Secret et al., 2017) did not include consideration and analysis of AS students, in this secondary data analysis, data from the initial RKA development project were analyzed to consider potential differences and similarities between AS and NAS students, including those with and without BSW undergraduate degrees in the NAS group, on RKA scores. Elsewhere, Secret et al. (2017) provided a detailed description of the initial data collection process and procedures. In this analysis, first, overall scores of AS and NAS on Posttest 2 of the RKA were compared. Next, comparisons between AS and NAS students were made on the scores of each subscale of the RKA. Data were then analyzed to compare across undergraduate majors (social work AS, social work NAS, psychology, and sociology or other) on overall RKA and subscale scores.

\section{Sample}

The sample of 336 respondents, students attending a large mid-Atlantic university's MSW program, included 67 AS and 269 NAS students (of 343 total respondents, $n=7$ declined to have their data included, for a response rate of $98 \%)$. Table 1 reports the demographic information of the sample. Approximately $93 \%$ of AS students and $91 \%$ of NAS students were female; the majority of respondents were between the ages of 21 and 30. Of the AS respondents, $97 \%$ noted having taken a research course prior to the MSW program, compared with only $69 \%$ of the NAS respondents; the majority of both groups reported having previously completed a statistics course $(80 \%=$ NAS; $85 \%=A S)$. All demographic information, including undergraduate major and AS status, was self-disclosed by student participants as part of the RKA instrument.

\section{Results}

An initial independent $t$ test was conducted to compare the overall mean Posttest 2 RKA scores of AS students $(N=67)$ and NAS students $(N=269)$. No significant difference $(t(121.03)=-1.64, p=.10)$ was found between AS students $(M=16.24, S D=2.81)$ and NAS students $(M=15.58, S D=3.46)$. Next, an independent $t$ test was conducted to examine potential differences between AS 
Table 1 Sample Demographics of Nonadvanced Standing Students and Advanced Standing Students

\begin{tabular}{|c|c|c|c|c|}
\hline \multirow[b]{2}{*}{ Variable } & \multicolumn{2}{|c|}{ Nonadvanced Standing } & \multicolumn{2}{|c|}{ Advanced Standing } \\
\hline & $n$ & $\%$ & $n$ & $\%$ \\
\hline \multicolumn{5}{|l|}{ Sex } \\
\hline Female & 244 & 90.7 & 62 & 92.5 \\
\hline Male & 25 & 9.3 & 5 & 7.5 \\
\hline \multicolumn{5}{|l|}{ Age } \\
\hline $21-30$ & 217 & 80.7 & 60 & 89.5 \\
\hline $31-40$ & 34 & 12.6 & 2 & 3.0 \\
\hline $41-50$ & 12 & 4.4 & 4 & 6.0 \\
\hline $51-60$ & 4 & 1.5 & 1 & 1.5 \\
\hline Missing & 2 & .74 & & \\
\hline \multicolumn{5}{|c|}{ Undergraduate Major } \\
\hline Social Work & 50 & 18.6 & 65 & 97.0 \\
\hline Psychology & 92 & 34.2 & & \\
\hline \multicolumn{5}{|l|}{ Sociology or } \\
\hline Other & 119 & 44.2 & & \\
\hline Missing & 8 & 3.0 & 2 & 3.0 \\
\hline \multicolumn{5}{|c|}{ Previous Research Methods Course } \\
\hline Yes & 186 & 69.1 & 65 & 97.0 \\
\hline No & 83 & 30.9 & 2 & 3.0 \\
\hline \multicolumn{5}{|c|}{ Previous Statistics Course } \\
\hline Yes & 215 & 79.9 & 57 & 85.1 \\
\hline No & 53 & 19.7 & 10 & 14.9 \\
\hline Missing & 1 & 0.37 & & \\
\hline
\end{tabular}

Note: Nonadvanced Standing N=269; Advanced Standing N=67.

and NAS students on RKA subscale scores (Table 2). Levene's Test for Equality of Variances indicated no differences in the variances between AS and NAS students for the Theory, Sampling, Design, and Ethics \& Practice subscales. Equal variances between AS and NAS students on the Measurement subscale were not assumed $(t(117.52)=-2.99, p=.003)$. However, there was a significant difference between AS students $(M=4.92, S D=1.31)$ and NAS students $(M=4.34, S D=1.69)$ on the Measurement subscale of the RKA.

Next considered were comparisons on RKA scores based on undergraduate major (AS social work undergraduate, NAS social work undergraduate, NAS psychology undergraduate, and NAS sociology or other undergraduate). Table 3 shows the results of a one-way ANOVA where significant differences between NAS social work undergraduate degree and all other undergraduate degrees were found on the total RKA score. Tukey honest significance test (HSD) post hoc comparisons indicated that the mean overall RKA score was significantly 
Table 2 Differences on the RKA Subscales Between Nonadvanced Standing Students and Advanced Standing Students

\begin{tabular}{|c|c|c|c|c|c|c|c|c|c|c|}
\hline & \multicolumn{3}{|c|}{$\begin{array}{c}\text { Nonadvanced } \\
\text { Standing Student }\end{array}$} & \multicolumn{3}{|c|}{$\begin{array}{c}\text { Advanced } \\
\text { Standing tudent }\end{array}$} & \multirow[b]{2}{*}{$d f$} & \multirow[b]{2}{*}{$t$} & \multirow[b]{2}{*}{$p$} & \multirow{2}{*}{$\begin{array}{l}\text { Cohen's } \\
\quad d\end{array}$} \\
\hline & $M$ & $S D$ & $N$ & $M$ & $S D$ & $N$ & & & & \\
\hline Theory & 3.91 & 1.40 & 255 & 3.88 & 1.35 & 64 & 317 & 0.16 & .874 & 0.02 \\
\hline Measurement & 4.34 & 1.69 & 259 & 4.92 & 1.31 & 63 & 117.5 & -2.99 & .003 & 0.38 \\
\hline Sampling & 3.21 & 0.79 & 262 & 3.30 & 0.80 & 67 & 327 & -0.85 & .394 & 0.11 \\
\hline Design & 2.03 & 1.06 & 256 & 1.97 & 0.92 & 60 & 314 & 0.41 & .684 & 0.06 \\
\hline Ethics \& practice & 2.26 & 0.69 & 265 & 2.35 & 0.54 & 66 & 329 & -1.01 & .313 & 0.15 \\
\hline
\end{tabular}

aTwo cases did not include undergraduate major (see Table 1); however, responses were included here because overall focus was comparing nonadvanced standing to advanced standing.

Table 3 Means, Standard Deviations, and One-Way ANOVA for Effects of MSW Student Undergraduate Major on Research Knowledge Assessment Total Score

\begin{tabular}{|c|c|c|c|c|c|c|c|c|c|c|}
\hline & \multicolumn{2}{|c|}{$\begin{array}{c}\text { Social Work } \\
\text { Nonadvanced } \\
\text { Standing } \\
(N=50)\end{array}$} & \multicolumn{2}{|c|}{$\begin{array}{l}\text { Social Work } \\
\text { Advanced } \\
\text { Standing } \\
(N=65)\end{array}$} & $\begin{array}{l}\text { Psych } \\
\qquad(\mathrm{N}=\end{array}$ & $\begin{array}{l}\text { ology } \\
\text { 92) }\end{array}$ & \multicolumn{2}{|c|}{$\begin{array}{c}\text { Sociology } \\
\text { or } \\
\text { Other } \\
(\mathrm{N}=119)\end{array}$} & & \\
\hline & $M$ & $S D$ & $M$ & $S D$ & $M$ & $S D$ & $M$ & $S D$ & & \\
\hline $\begin{array}{l}\text { RKA Total } \\
\text { Score }\end{array}$ & 14.04 & 3.21 & 16.14 & 2.79 & 16.32 & 3.34 & 15.57 & 3.51 & 3,322 & $\begin{array}{llll}5.76 & 001 & 0.05\end{array}$ \\
\hline
\end{tabular}

Note: $A N O V A=$ analysis of variance; $M S W=$ master's of social work.

different between NAS social work undergraduate $(M=14.04, S D=3.21)$ and each of the other three groups: AS social work undergraduate $(M=16.14$, $S D=2.79)$, NAS psychology undergraduate $(N=16.32, S D=3.34)$, and NAS sociology or other undergraduate $(N=15.57, S D=3.51)$.

A one-way ANOVA was conducted to examine between-group differences on RKA subscale scores based on undergraduate major (Table 4). No significant differences between groups were found for the Sampling, Design, or Ethics \& Practice subscales. Significant differences between groups were found for the Theory and Measurement subscales. Tukey HSD post hoc comparisons indicated that the mean Theory subscale score for NAS social work undergraduate major ( $M=3.41, S D=1.34$ ) was significantly different from the mean Theory subscale score of NAS psychology undergraduate major MSW students $(M=4.23, S D=1.41)$. Significant differences were also found on the 


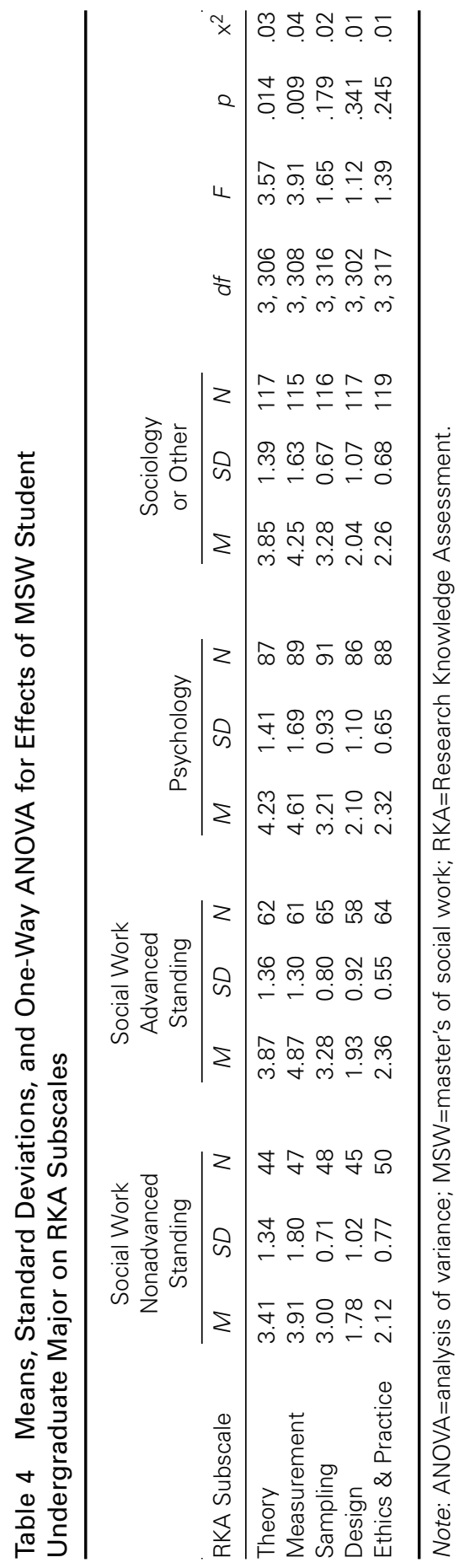


Measurement subscale score for NAS social work majors $(M=3.91, S D=1.80)$ and AS social work major MSW students $(M=4.87, S D=1.30)$.

Based on the results of the one-way ANOVAs and given the exploratory nature of this study, a series of ANCOVAs were run to examine if there was a statistically significant difference between MSW student groups by undergraduate major on RKA subscale scores when controlling for age and having taken a previous research course. For this analysis, age was grouped into two categories (21-30 and 31-60), given the positively skewed data on age in the 21-30 category and previous research, which was categorical. Similar to the results of the ANOVAs, there were no significant effects of MSW student undergraduate major on the Sampling, Design, and Ethics \& Practice subscale scores after controlling for age and previous research course. For the Theory subscale, after Levene's test indicated equality of variance could be assumed $(F(3,305)=.253, p=.859)$, there was significant difference in the mean Theory subscale score between undergraduate majors when controlling for age and previous research $F(3,303)=3.93, p=.009$. Post hoc tests showed a difference between the mean scores for NAS $(M=3.41 ; A d j M=3.34)$ and Psychology $(M=4.23 ; A d j M=4.19)$ on the Theory subscale score. For the Measurement subscale, Levene's test did not indicate an equality of variance could be assumed $(F(3,306)=3.74, p=.012)$. There was however, a significant difference in the mean Measurement subscale score between undergraduate majors when controlling for age and previous research $F(3,304)=2.88, p=.036$. Post hoc tests found a difference between the mean scores for NAS $(M=3.96 ; \operatorname{Adj} M=3.89)$ and AS $(M=4.87 ; A d j M=4.78)$ on the Measurement subscale score. It should be noted that the effect size as indicated by the partial eta squared were low for both Theory (partial $\eta^{2}=.037$ ) and Measurement (partial $\eta^{2}=.028$ ).

In the data analysis above, the adjustment for multiple testing was only considered for each subscale score. The Bonferroni correction was not done across scales because of the exploratory nature of this research study (Rothman, 1990). Furthermore, the potential for overcorrecting due to the conservativeness of the Bonferroni correction to address Type I error increases the potential for Type II error (Feise, 2002; Perneger, 1998). To address this concern, a MANOVA was conducted to determine whether there were any differences on the RKA subscales scores by MSW students grouped by undergraduate major. There was not a statistically significant difference in RKA subscale scores based on students' undergraduate major, $F(15,756.80)=1.63$, $p=.06$; Wilk's $\eta=.916$, partial $\eta^{2}=.03$. Based on these results, a MANCOVA exploring age and previous research experience as covariates was not conducted. 


\section{Discussion}

This article describes a secondary data analysis comparing the research knowledge of AS and NAS MSW students, and among different undergraduate majors. The main findings of the study include the lack of difference between AS and NAS on the RKA and most subscales, including Theory, Sampling, Design, and Ethics \& Practice. The finding of no difference between AS and NAS groups echo the findings of prior research (e.g., Carrillo \& Thyer, 1994; Thyer et al., 1996). Differences between the groups were noted, however, on the Measurement subscale of the RKA, indicating that AS students, on average, score higher than their NAS counterparts on measurement-targeted questions. This finding contrasts with O'Neil's (1980) conclusion, which indicated that AS students performed worse than NAS students on field supervisors' assessment of practice skills, another important educational outcome. This difference could be the result of more AS students reporting having taken a research course prior to the MSW program than NAS students, as well as differentials in time passed since the student was in school, with advanced standing students having to pursue their MSW within 5 years, according to the host university's criteria. Less time out of the research classroom could translate into higher scores on measurement-related questions. Additionally, and perhaps not surprising to BSW educators, AS students are typically strong students, having met a high academic performance threshold to achieve advanced standing status (a minimum of a 3.0 GPA at the host institution); thus higher scores could be the result of a higher capacity to retain the knowledge. Last, it is possible that perhaps AS students learn about measurement topics in a way that is somehow different from how those same topics are covered in the foundation year curriculum for NAS MSW students. This is a heartening finding for BSW educators - that AS students are acquiring and retaining research knowledge at least as well, and even more so on measurement topics, as their NAS colleagues. That is, based on this finding, the research content afforded at the BSW level is comparable to the content of the MSW foundation year research for students with AS.

In considering the differences in research knowledge between different undergraduate majors, comparisons were made between RKA scores of students with and without a BSW undergraduate degree and other majors. Of importance, students who earned a BSW without AS scored lower on the total RKA than any of the other three student groups (AS, NAS psychology, and NAS sociology or other). In addition, NAS students with a BSW scored significantly lower than AS students with a BSW on the Measurement subscale, 
and lower than NAS psychology students on the Theory subscale. As above, factors related to whether a student has earned AS likely influence the differences in RKA scores between BSW undergraduates without AS and all other student groups, including length of time out of the classroom, academic performance, and aptitude.

The highest scoring group on the RKA, overall, comprised NAS psychology majors. The high performance of psychology undergraduates is not necessarily a surprising finding, as psychology undergraduates take intensive coursework focused on statistics and research. Perhaps the lower performance of AS and NAS social work undergraduate majors, as compared to psychology undergraduates, is related to the decreased interest in research or higher anxiety, as highlighted by Green et al. (2001) and Royse and Rompf (1992), or decreased exposure to previous research and statistics courses. However, when controlling for student age and having taken a previous research methods course, the findings were similar.

Even in considering reasonable explanations for disparities in RKA scores between NAS BSW students and all other undergraduate groups, it is still disconcerting to find that NAS BSW students do not seem to retain, or perhaps acquire, research knowledge from their research course(s) in their BSW programs. It is even more revealing that, overall, scores on the RKA for all students with BSWs were quite low. Out of the 25 total questions included on the RKA, NAS and AS students missed on average 11 and nine questions, respectively. These overall scores, and the higher performance of NAS psychology students, lend support to an increase in efforts to adjust and specifically target select topic areas in BSW research curriculum to best prepare BSW students for research-informed generalist practice and graduate education. Specific suggestions are offered in the Implications section.

\section{Limitations}

There are several important limitations for the current study that should be considered when interpreting its findings. First, because the RKA was developed by one institution, reflecting its curriculum in particular, generalizability of these findings is limited. However, this study, using data from an instrument development study, is a beginning step in better understanding differences in research knowledge between AS and NAS students with various undergraduate backgrounds. A second important limitation includes potential biases imposed by the admission criteria into this one program's AS. Indeed, selection parameters for AS at other institutions are likely to be different from those at 
the host institution, impeding the generalizability of the findings. Additionally, as this analysis makes use of Posttest 2 data (administered at the beginning of the concentration year), the potential influence of summer courses for AS students, a common practice at this institution, were not considered. As a result, future studies should consider whether more or less rigorous admission criteria for AS students and summer or bridge courses influence performance on the RKA. In addition, given the low reliability score from the KR-20 for this sample, further research is needed to assess the reliability of the RKA with larger and more diverse samples. Given that the RKA is a recently developed instrument, more research is needed to confirm its overall validity and reliability, particularly with students from other BSW and MSW programs. Finally, future studies making use of the RKA might consider using other evidence to establish validity, including assessing the RKA's predictive validity of students' course grades.

\section{Implications}

The findings from this study highlight several areas of BSW social work research curriculum and programmatic additions or adjustments for consideration. First, the finding of comparability between AS and NAS as a collective group on overall RKA score gives support to the assertion that foundation-level research curriculum is provided in BSW programs, as well as in the first year of the MSW. This also supports the notion that BSW undergraduates who received AS status are suitably prepared for the MSW level with respect to the research curriculum. However, for students with BSWs who did not pursue their MSWs with AS, total scores on the RKA were significantly lower than all other student groups. This may indicate a need for adjustments in curriculum to better prepare these students for graduate school. Specifically, the NAS BSW group had significantly lower scores on the Measurement and Theory subscales, highlighting the educational content in these areas, which may need to be emphasized in BSW research curriculum.

Although AS students are performing well, their strengths may be in their overall academic aptitude, their affinity or lack of anxiety regarding research content, or the limited time since they were last in the classroom, making the mastery of RKA topics more likely in their case. To address the lower performance of NAS BSW students, efforts to better equip these students for research content in MSW programs can begin by focusing on education they receive in the BSW program. For example, this study's NAS non-BSW participants reported taking more statistics courses than research methods 
courses in their undergraduate education, in addition to more research methods courses than NAS BSW students overall, which may partly be responsible for the lower Measurement subscale score of NAS BSW students. These courses, and specifically statistics content, likely emphasize measurement and level of measurement as fundamental topics, content that NAS BSW students may not be receiving in full. As such, a specific focus on BSW research courses on the importance of the measurement of constructs, variables, and levels of measurement, and how these are related to statistics, may prove useful. Helping students understand that although statistics help with the analysis of numerical data, the importance of rigorously measured constructs determines whether statistical analysis will provide anything of use.

Similarly, NAS BSW students may struggle to understand how theory functions within the research process, as indicated by lower Theory subscale scores. Curriculum efforts to emphasize the role theory plays in both deductive and inductive research may help students to understand not only why theory can be important in research but also the connection between practice, theory, and research (Drisko, 2014). As Drisko (2014) notes, theories from human behavior in the social environment courses could be examined and critiqued with students to determine their empirical support (evidence base) followed by a discussion of the implications for practice. If this connection is strengthened, BSW graduates may better conceptualize the integration and intersection of theory, research, and practice, potentially leading to greater competence with theoretical and measurement based topics due to students' better understanding of the application of these areas to social work.

Given the expectations for student engagement in research (CSWE, 2015b) and to further address potential challenges in acquiring research knowledge, another suggestion is to provide BSW students with more opportunities to understand the connections between research and social justice. As BSW graduates highly endorse the pursuit of social justice as a primary goal of the profession (Weiss, 2005), strengthening the link between research and social justice content may increase student engagement. Discussing a pedagogical approach to engaging students in research, which may be useful in strengthening this link, Kranke, Brown, Atia, and Knotts (2015) suggests a learning activity aimed at helping students connect the impact of research on alleviating social problems. These authors suggest an assignment in which students select a research topic and engage in exploration of social networking sites about their chosen issue, including first-person accounts and common understanding of the issue, to ascertain level of awareness (Kranke et al., 2015). Using this snapshot of the field, students then may go on to conduct literature 
reviews confirming what they learned anecdotally on social media or even design their own studies to build upon limited understanding they identify in their exploration.

BSW graduates globally endorse enhancing individual well-being as a goal of social work (Weiss, 2005), indicating that strengthening the link between research and practice may enhance student's research knowledge and retention. Research methods courses designed to underscore that research can be used to assess micro and macro practices and as a tool to address social (in)justice may help students understand not only the practicality of research but also the necessity of research within the profession of social work (Ponnuswami \& Harris, 2017). Ways to encourage this include taking the classroom content into the real world-compelling students to engage in research projects connected to their field placements or with community-based agencies and organizations with which social work programs are affiliated (Anderson, 2002; Blakemore \& Howard, 2015; Lucero, 2015; Satka, Käärï̈nen, \& Yliruka, 2016). Students' increased understanding of research and realization of the need for research in their role as a future social worker have been found when students conducted a program evaluation of their own social work program (Jacobson \& Goheen, 2006).

Furthermore, faculty members could also facilitate more opportunities to engage BSW students in their research projects either as assistants or simply by including updates of progress on faculty projects into class discussions (Freymond et al., 2014; Tompkins, Rogers, \& Cohen, 2009). Many BSW programs are already encouraging these efforts, but again, differences truly exist among programs (Rubin, Valutis, \& Robinson, 2010). Future research might investigate how and when research content is implemented into the BSW curriculum, describing these differences and how they may or may not influence the acquisition and retention of research knowledge of BSW students. Availing students of specific exercises to engage in research experiences could be beneficial in not only increasing research knowledge acquisition and retention but also encouraging a better appreciation for research within the profession of social work (Whipple, Hughes, \& Bowden, 2015).

Finally, in educators' efforts to prepare BSWs for generalist research-informed practice or graduate-level research practicum, it is important to examine at a programmatic level the degree of commitment shown to research as an integral part of the social work profession. Indeed, the relationship between research and professional social work practice is a turbulent one, deeply rooted in the profession's history (Adam, Zosky, \& Unrau, 2004). The debate is international, with faculty members of social work programs in the United Kingdom 
expressing reservations and resistance to the importance and feasibility of research education for social workers (MacIntyre \& Paul, 2013). One way to express the value of research education at a programmatic level is to engage in program self-assessment of the research knowledge acquisition and retention of BSW students. One finding from the present study is that overall, regardless of student group-AS or NAS — the RKA scores are low, indicating a programmatic need to monitor student progress in the research curriculum and after BSW graduation. For BSW programs, this could involve following up with graduates to ascertain the extent to which they are engaging in researchinformed generalist practice and/or continued assessment at the MSW level of students with BSWs, both AS and NAS. Although students may achieve the course outcomes in BSW research classes, earning credit for graduation from BSW programs, further study will reveal if knowledge was retained to meet the overall goal of preparing social workers capable of using research to improve their practice and best serve clients.

\section{References}

Adam, N., Zosky, D. L., \& Unrau, Y. A. (2004). Improving the research climate in social work curricula. Journal of Teaching in Social Work, 24(3-4), 1-18. doi:10.1300/J067v24n03_01

Anderson, S. G. (2002). Engaging students in community-based research: A model for teaching social work research. Journal of Community Practice, 10(2), 71-87. doi:10.1300/J125v10n02_05

Beddoe, L. (2011). Investing in the future: Social workers talk about research. British Journal of Social Work, 41(3), 557-575. doi:10.1093/bjsm/bcq1385

Blakemore, T., \& Howard, A. (2015). Engaging undergraduate social work students in research through experience-based learning. Social Work Education, 34, 861-880. doi:10.1080/02615479.2015.1065809

Bodner, G. M. (1980). Statistical analysis of multiple-choice exams. Journal of Chemical Education, 57(3), 188-190.

Bremner, J., \& Zastrow, C. (2008). Advanced standing revisited: Current status, structure, and issues. Journal of Teaching in Social Work, 28(1/2), 101-116. doi: 10.1080/08841230802179068

Carrillo, D. F., \& Thyer, B. A. (1994). Advanced standing and two-year program MSW students: An empirical investigation of foundation interviewing skills. Journal of Social Work Education, 30, 377-385. doi:10.1080/10437797.1994.10672247 
44 JOURNAL OF BACCALAUREATE SOCIAL WORK

Council on Social Work Education (CSWE). (2015a). 2015 Statistics on social work education in the United States. Retrieved from https://www.cswe.org/CMSPages/GetFile.aspx?guid=5e8fc9fa-9299-4b54acc6-0e6583323fla

Council on Social Work Education (CSWE). (2015b). Educational policy and accreditation standards. Retrieved from https://cswe.org/Accreditation/Standards-and-Policies/2015-EPAS

Council on Social Work Education (CSWE). (2016). Annual statistics on social work education in the United States-2015. Retrieved from https://www.cswe.org/CMSPages/GetFile.aspx?guid=992f629c-57cf-4a748201-1db7a6fa4667

Council on Social Work Education (CSWE). (2017). 2016 Statistics on social work education in the United States. Retrieved from https://www.cswe.org/CMSPages/GetFile.aspx?guid=6e8bc9e7-ebd6-4288bc7a-d2d427d68480

Daley, M. R. (2015). Commemorating the BSW. Journal of Baccalaureate Social Work, 20, vii-ix. doi:10.18084/1084-7219.20.1

DeVellis, R. F. (2017). Scale development: Theory and applications (4th ed.). Thousand Oaks, CA: SAGE.

Drisko, J. (2014). Split or synthesis: The odd relationship between clinical practice and research in social work and in social work education. Clinical Social Work Journal, 42(2), 182-192. doi:10.1007/s10615-014-0493-2

Epstein, I. (1987). Pedagogy of the perturbed: Teaching research to the reluctant. Journal of Teaching in Social Work, 1, 71-89. doi:10.1300/J067v01n01_06

Feise, J. R. (2002). Do multiple outcomes measures require a $p$-value adjustment? BMC Medical Research Methodology, 2(8), 1-4. doi:10.1186/1471-2288-2-8

Fortune, A. E., Green, R. G., \& Kolevzon, M. S. (1987). In search of the continuum: Graduate school performance of BSW and non-BSW degree holders. Journal of Sociology and Social Welfare, 14, 169-189. Retrieved from http://scholarworks.wmich.edu/jssw/vol14/iss1/17

Freymond, N., Morgenshtern, M., Duffie, M., Hong, L., Bugeja-Freitas, S., \& Eulenberg, J. (2014). Mapping MSW research training. Journal of Teaching in Social Work, 34, 248-268. doi:10.1080/08841233.2014.912998

Gredig, D., \& Bartelsen-Raemy, A. (2018). Exploring social work students' attitudes toward research course: Predictors of interest in research-related courses among first year students enrolled in a bachelor's programme in 
Switzerland. Social Work Education: The International Journal, 37(2), 190208, doi:10.1080/02615479.2017.1389880

Green, R. G., Bretzin, A., Leininger, C., \& Stauffer, R. (2001). Research learning attributes of graduate students in social work, psychology, and business. Journal of Social Work Education, 37, 333-341. Retrieved from http://www.jstor.org/stable/23043601

Harlen, W. (2007). Criteria for evaluating systems for student assessment. Studies in Educational Evaluation, 33, 15-28. doi:10.1016/j.stueduc.2007.01.003

Jacobson, M., \& Goheen, A. (2006). Engaging students in research: A participatory BSW program evaluation. Journal of Baccalaureate Social Work, 12(1), 87-104. doi:10.18084/1084-7219.12.1.87

Jani, J. S., Sowbel, L., Smith-Osborne, A., Yum, J., Mollette, A., Hall, D., \& Bina, R. (2009). Perceived preparedness and knowledge of substance abuse among recent MSW graduates: Advanced standing revisited. Journal of Social Work Practice in the Addictions, 9, 381-399. doi:10.1080/153325609033284487

Knight, C. (1993). A comparison of advanced standing and regular master's students' performance in the second-year field practicum: Field instructors' assessments. Journal of Social Work Education, 29, 309-317. Retrieved from http://www.jstor.org/stable/41346394

Kranke, D., Brown, J. L., Atia, M., \& Knotts, G. (2015). A pedagogical approach to engaging social work students in research. Social Work Education, 34, 895-901. doi:10.1080/02615479.2015.1065810

Lucero, J. L. (2015). Engaging undergraduate social work students in community-based research: Developing research skills through hands-on learning. Council on Undergraduate Research, 35(4), 18-24. Retrieved from https://www.cur.org/download.aspx?id=3153

Maschi, T., Wells, M., Slater, G. Y., MacMillan, T., \& Ristow, J. (2013). Social work students' research-related anxiety and self-efficacy: Research instructors' perceptions and teaching innovations. Social Work Education, 32, 800-817. doi:10.1080/02615479.2012.695343

MacIntyre, G., \& Paul, S. (2013). Teaching research in social work: Capacity and challenge. British Journal of Social Work, 43, 685-702. doi:10.1093/bjsw/bcs010

McGahee, T. W., \& Ball, J. (2009). How to read and really use an item analysis. Nurse Educator, 34(4), 166-171. doi:10.1097/NNE.0b013e3181aaba94

Morgenshtern, M., Freymond, N., Agyapong, S., \& Greeson, C. (2011). Graduate social work students' attitudes toward research: Problems and 
prospects. Journal of Teaching in Social work, 31(5), 1-17. doi:10.1080/08841233.2011.615287

Nelson, K. (1983). Differences in graduate and undergraduate performance in a core research course. Journal of Education for Social Work, 19(2), 77-84. Retrieved from http://www.jstor.org/stable/23038543

O'Neil, M. J. (1980). A comparative study of social workers from one and twoyear graduate social work programs. Journal of Education for Social Work, 16(3), 297-304. Retrieved from http://www.jstor.org/stable/23038532

Perneger, T. V. (1998). What's wrong with Bonferroni adjustments. British Medical Journal, 316(7139), 1236-1240. Retrieved from http://www.jstor.org/stable/25178955

Ponnuswami, I., \& Harris, N. (2017). Teaching research methods to social work students in India and Australia: Reflections and recommendations. Social Work Education, 36, 690-701. doi:10.1080/02615479.2017.1335299

Quaigrain, K., \& Arhin, A. K. (2017). Using reliability and item analysis to evaluate a teacher-developed test in educational measurement and evaluation. Cogent Education, 4, 1-11. doi:10.1080/2331186X.2017.1301013

Raymond, G. T., \& Atherton, C. R. (1991). Blue smoke and mirrors: The continuum in social work education. Journal of Social Work Education, 27(3), 297-305. Retrieved from http://www.jstor.org/stable/23042666

Rothman, K. J. (1990). No adjustments are needed for multiple comparisons. Epidemiology, 1(1), 43-46. doi:10.1097/00001648-199001000-00010

Royse, D., \& Rompf, E. L. (1992). Math anxiety: A comparison of social work and non-social work students. Journal of Social Work Education, 28, 270-277. doi:10.1080/10437797.1992.10778780

Rubin, D., Valutis, S., \& Robinson, B. (2010). Social work education and student research projects: A survey of program directors. Journal of Social Work Education, 46, 39-55. doi:10.5175/JSWE.2010.200800040

Rudner, L. M., \& Schafer, W. D. (2002). What teachers need to know about assessment. Washington, DC: National Education Association.

Satka, M., Kääriänen, A., \& Yliruka, L. (2016). Teaching social work practice research to enhance research-minded expertise. Journal of Teaching in Social Work, 36(1), 84-101. doi:10.1080/08841233.2016.1128779.

Secret, M., Abell, M. L, Ward, C. J., Charles, J. L. K., \& Perkins, N. H. (2017). Research knowledge assessment: A study of MSW students' acquisition and retention of research knowledge. Journal of Social Work Education, 53, 480-494. doi:10.1080/10437797.2016.1266977 
Sheafor, B. W. (2001). Three decades of baccalaureate social work: A grade card on how professionalization of the BSW has played out. Journal of Baccalaureate Social Work, 6(2), 25-43. doi:10.18084/1084-7219

Specht, H., Britt, D., \& Frost, C. (1984). Undergraduate education and professional achievement of MSWs. Social Work, 29, 219-224.

Thyer, B. A., Vonk, E., \& Tandy, C. C. (1996). Are advanced standing and two-year program MSW students equivalently prepared? A comparison of BSW licensure examination scores. Arete, 20(2), 42-46.

Tompkins, C., Rogers, A., \& Cohen, H. (2009). Promoting undergraduate student research collaboration: Faculty perceptions of benefits and challenges. Journal of Baccalaureate Social Work, 14(1), 1-13. doi:10.5555/basw.14.1.b172444649872588

Weiss, I. (2005). Is there a global common core to social work? A cross-national comparative study of BSW graduate students. Social Work, 50, 101-110. doi: $10.1093 / \mathrm{sw} / 50.2 .101$

Whipple, E. E., Hughes, A., \& Bowden, S. (2015). Evaluation of a BSW research experience: Improving student research competency. Journal of Teaching in Social Work, 35, 397-409. doi:10.1080/08841233.2015.1063568

Jennifer L. K. Charles, PhD, is assistant professor at The Catholic University of America in Washington, DC. Nathan H. Perkins, PhD, is assistant professor at Loyola University, Chicago, IL. Christopher J. Ward, MSW, is online program coordinator at Winthrop University, Rock Hill, SC. Melissa L. Stewart, PhD, is associate professor at Virginia Commonwealth University in Richmond, VA. Mary C. Secret, PhD, is associate professor at Virginia Commonwealth University. 
Copyright of Journal of Baccalaureate Social Work is the property of Journal of Baccalaureate Social Work and its content may not be copied or emailed to multiple sites or posted to a

listserv without the copyright holder's express written permission. However, users may print, download, or email articles for individual use. 